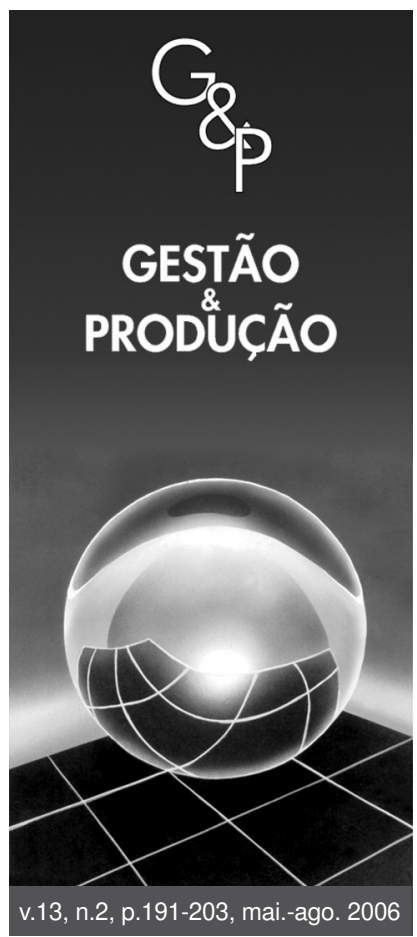

\title{
IMPLEMENTAÇÃO DE PROGRAMAS DE QUALIDADE: UM SURVEYEM EMPRESAS DE GRANDE PORTE NO BRASIL
}

\author{
Silvia Helena Boarin Pinto \\ União das Faculdades da Organização Paulistana Educacional e Cultural, \\ UNOPEC, CEP 06635-020, São Paulo, SP, \\ e-mail: shboarin@uol.com.br \\ Marly Monteiro de Carvalho \\ Linda Lee Ho \\ Departamento de Engenharia de Produção, \\ Escola Politécnica da Universidade de São Paulo, EPUSP, \\ CEP 05508-900, São Paulo, SP, \\ e-mails: lindalee@usp.br, marly.carvalho@poli.usp.br
}

Resumo

Recebido em 01/11/2005

Aceito em 30/5/2006

O objetivo deste trabalho é identificar os principais aspectos da implementação dos programas de qualidade em empresas brasileiras, a partir dos modelos mais difundidos e implementados como a certificação de sistemas de qualidade nas normas ISO 9000, o Seis Sigma e o Total Quality Management (TQM), fazendo uma análise comparativa e crítica de sua adoção pelas organizações e estudando as relações existentes entre eles, a complementaridade e as redundâncias. O tema é extremamente relevante no cenário atual, em que as companhias investem quantias significativas em diversos programas de melhoria da qualidade e possuem enormes dificuldades para avaliar o impacto estratégico, bem como o respectivo valor agregado. A metodologia adotou elementos da análise quantitativa, isto é, uma pesquisa do tipo survey. O universo para a coleta de dados foi extraído da relação "Ranking Valor 1.000", que contém as 1.000 maiores empresas brasileiras, publicadas no anuário do jornal "Valor Econômico", ano-base de 2004, partindo-se do pressuposto de que, nestas empresas, estarão os embriões dos modelos emergentes de gestão da qualidade. Posteriormente, as respostas obtidas por meio de questionários foram analisadas com o auxílio de um programa estatístico. A análise concluiu que as empresas que implantaram o programa Seis Sigma são as de maior tradição em qualidade, ou seja, adotaram outros programas anteriormente; as organizações que mais investiram em qualidade, pela adoção de programas, obtiveram sucesso nos indicadores de desempenho; e as principais causas do insucesso dos programas de qualidade ISO 9000, Seis Sigma e TQM nas organizações analisadas foram a escassez de recursos financeiros para a correta implantação e o frágil apoio da direção da empresa.

Palavras-chave: programas de qualidade, Seis Sigma, ISO 9000, TQM.

\section{Introdução}

As transformações nas áreas da qualidade e da produtividade, ao final do século XX e início do século XXI, foram extremamente relevantes. Os motivos que acarretaram tais alterações foram: a intensa competição entre as organizações, dentro de seus países e fora deles; a diminuição das barreiras comerciais, com a criação de grandes blocos econômicos; e a diminuição do crescimento econômico mundial, em face da consolidação da qualidade de produtos e serviços como sendo fundamental para a sobrevivência das empresas. Os consumidores passaram a exigir maior qualidade nos produtos e serviços a um preço menor, isto é, a opinião dos clientes passou a ser um fator primordial. Assim, as estratégias da qualidade utilizadas até então necessitam de atualização, para poderem ser aplicadas nas companhias que pretendem competir na economia mundial.

A adoção de normas como a ISO 9000, a ISO 14000 e a $Q S 9000$, de premiações como o Malcolm Baldrige e o Prêmio Nacional de Qualidade (PNQ), de programas como o Seis Sigma e o Total Quality Management (TQM), 
constituem uma alternativa para as empresas poderem concorrer nos moldes do mercado atual (Shankar, 2003). Hendricks e Singhall (1997) argumentam ainda, baseados em estudos empíricos, que a efetiva adoção dos programas de qualidade pode trazer impacto positivo no crescimento das vendas e na redução dos custos. Em estudo posterior, os mesmos autores compararam o desempenho das empresas que efetivamente adotavam programas de qualidade, utilizando como parâmetro de análise o comportamento das ações dessas empresas, constatando também desempenho superior (Hendricks e Singhall, 2001).

Levantamentos empíricos no contexto brasileiro ainda são escassos. Neste artigo, é apresentado um levantamento do tipo survey em empresas de grande porte no Brasil, buscando extrair evidências empíricas de que os investimentos em qualidade trouxeram retornos, além de identificar as principais tendências em curso nos programas de qualidade e os principais gargalos no processo de implementação destes programas.

O artigo está estruturado em cinco seções. As seções 2 e 3 apresentam a síntese da discussão teórica dos temas abordados e a abordagem metodológica proposta para a pesquisa de campo, respectivamente. A seção 4 apresenta os resultados do levantamento feito em 198 empresas brasileiras de grande porte. Finalmente, a seção 5 traz as conclusões, limitações e recomendações para futuros trabalhos.

\section{Os programas de qualidade}

Os modelos de gestão da qualidade evoluíram e se difundiram ao longo do último século. A área se consolidou nos Estados Unidos, em meados da década de 1940, com o surgimento da primeira associação de profissionais da área de qualidade - a Society of Quality Engineers em 1945 e, posteriormente, da American Society for Quality Control (ASQC) em 1946, atualmente American Society for Quality (ASQ). Pouco depois, em 1950, também seria criada a associação japonesa de cientistas e engenheiros, a Japan Union of Scientists and Engineers (JUSE), com papel importante na área de qualidade (Carvalho e Paladini, 2005).

Os teóricos da área de qualidade tiveram muita influência nas organizações como é o caso de Juran, Feingenbaum, Deming, Crosby, Ishikawa, dentre outros (Juran e Gryna, 1992; Feingenbaum, 1954; Deming, 1990; Crosby, 1990; Ishikawa, 1997). A abordagem de qualidade nas organizações, passou por várias eras desde um enfoque de inspeção, passando pelo controle, garantia e gestão da qualidade (Garvin, 1988).

Neste trabalho, foram analisados três modelos de gestão de qualidade, quais sejam: ISO 9001:2000, o Total Quality Management (TQM) e o Seis Sigma.

Carvalho e Paladini (2005) afirmam que, em meio à expansão da globalização, surgiu o modelo normativo da International Organization for Standardization (ISO) para a área de Gestão da Qualidade, a série 9000, Sistemas de Garantia da Qualidade. As normas ISO série 9000 foram editadas pela primeira vez em 1979 pela International Organization for Standardization (ISO) $\mathrm{e}$, rapidamente, tornaram-se uma referência para a gestão da qualidade das empresas. Em dezembro de 2003, mais de 500 mil certificados haviam sido emitidos em 149 países de todos os continentes. No Brasil, até janeiro de 2005, mais de 5.800 certificados haviam sido obtidos em todo o território nacional, com uma maior concentração nos Estados de São Paulo, Paraná, Minas Gerais e Rio Grande do Sul. As normas ISO 9000 representam uma condição essencial para empresas que pretendem exportar seus produtos, principalmente para os Estados Unidos e países da Europa (CB-25, 2005). O sucesso na implantação da referida norma pode ser demonstrado em diversos países de todos os continentes, como a Austrália, onde a certificação é obrigatória para empresas que pretendem negociar com organismos governamentais ou com as grandes companhias privadas (Love, 2003).

A última revisão da norma, chamada de ISO 9001:2000, foi editada no ano de 2000 e representa um avanço, quando comparada com a versão anterior, pois possui um vocabulário mais simplificado, maior facilidade de utilização em empresas de serviços e maior conformidade com a norma de gestão ambiental ISO 14000 (os requisitos estruturais e organizacionais dos dois sistemas de gestão foram elaborados para serem compatíveis, fazendo com que a implantação das duas normas fosse facilitada). Outras alterações relevantes foram: a orientação por estrutura de processos; a ênfase na melhoria contínua dos produtos e serviços; o maior comprometimento da alta administração com o sistema de gestão da qualidade; a ênfase na medição e análise dos resultados das organizações; e o monitoramento da satisfação dos clientes (Dobb, 2002; Landon, 2003; Robitaille, 2003; Warnack, 2003).

Existem diversos modelos de Total Quality Management $(T Q M)$ disponíveis na literatura, contudo, desde o seu surgimento na década de 1990, alguns construtos podem ser identificados nas diversas abordagens, quais sejam: foco nos clientes; liderança e comprometimento da alta direção; envolvimento e participação da força de trabalho; relacionamento com os fornecedores e parceiros; gestão por processos, gestão por diretrizes; melhoria contínua, de processos, produtos e serviços; e análise de fatos e dados relativos à qualidade. As principais etapas de implantação podem ser resumidas em: a orientação (estabelecer objetivos e determinar novas estruturas organizacionais); a atribuição de poder (deve-se delegar poder para sincronizar e adequar o TQM aos objetivos da empresa); e o alinhamento (todos os colaboradores envolvidos nos diversos processos devem ser treinados no uso das téc- 
nicas e ferramentas do $T Q M$ e incentivados a aplicá-las constantemente em produtos ou serviços) (Flynn et al., 1994; Powell, 1995; Ahire et al., 1996; Shiba et al., 1997; Martínez-Lorente et al., 1998; Motwani, 2001).

O programa mais recente de Gestão da Qualidade surgiu no final da década de 1980, na Motorola, chamado Seis Sigma. Esse programa apresenta várias características dos modelos anteriores, como o pensamento estatístico típico da época de maior ênfase no controle da qualidade e análise e solução de problemas, apresentando uma preocupação com o uso sistemático das ferramentas estatísticas, seguindo um ciclo batizado de Define-measureanalyse-improve-control (DMAIC), sigla que representa as etapas de definir, medir, analisar, melhorar e controlar, o que também remete ao ciclo Plan-do-check-action (PDCA), conforme Carvalho e Paladini (2005). Estes autores ressaltam, contudo, que esse método vai além do pensamento estatístico, pois promove um alinhamento estratégico da qualidade, desdobrada em projetos prioritários. Além disso, existe forte ênfase na relação custobenefício dos projetos de melhoria, cujos ganhos, em algumas empresas, somam cifras expressivas. Ressalte-se que a metodologia proposta, extremamente disciplinada e prescritiva, direciona o desenvolvimento de processos, produtos e serviços com um índice de 3,4 defeitos por milhão.

Alguns autores definem o Seis Sigma como uma estratégia gerencial de mudanças, visando à melhoria de processos, produtos e serviços organizacionais, amplamente direcionada à satisfação dos clientes. Alguns dos construtos do modelo Seis Sigma remetem ao TQM, quais sejam: a importância do conhecimento das necessidades dos clientes para a realização dos estudos; a utilização disciplinada de fatos reais, dados e verificações estatísticas; o apoio incondicional da direção da empresa; e a melhoria contínua. O Seis Sigma não considera a qualidade em seu sentido tradicional, isto é, a conformidade com as normas e os requisitos internos da empresa, mas define qualidade como sendo o valor agregado por um amplo esforço produtivo, buscando atingir os objetivos estratégicos planejados por estudos realizados pela companhia (Pande et al., 2001; Perez-Wilson, 2000; Pyzdek, 2003; Rotondaro, 2002).

Alguns dos benefícios da implementação do Seis Sigma relatados na literatura podem ser resumidos nos seguintes itens: a diminuição dos custos empresariais; o aumento significativo da qualidade e da produtividade em produtos e serviços; o acréscimo no número de clientes e sua retenção; a eliminação das atividades que não agregam valor ao processo; e a benéfica mudança cultural promovida na organização. Um dos principais problemas do Seis Sigma é que diversas empresas não o compreendem corretamente e, em decorrência disso, a transmissão de seus conceitos para todas as áreas organizacionais torna-se demasiadamente prejudicada (Connor, 2003; Cooper e Noorman, 2003; Olexa, 2003; Phillips, 2002; Watson, 2003; Welch, 2003a e 2003b).

As relações entre os modelos citados, ou seja, as normas internacionais ISO 9000, o TQM e o Seis Sigma, representam um aspecto proeminente para as organizações, pois em várias empresas estes modelos coexistem e podem apresentar características sinérgicas.

Os programas de melhoria são de extrema relevância, porém devem estar integrados, pois, caso contrário, a implantação e a manutenção isolada dissipam recursos humanos e financeiros, causam competição desnecessária entre setores da empresa e acarretam o descrédito dos colaboradores (Hammer, 2002). Neste contexto, diversos pesquisadores têm estudado o impacto destes programas nos resultados das organizações, bem como os fatores críticos de sucesso na implementação destes programas.

Um dos primeiros estudos empíricos foi realizado por Powell (1995), que investigava a relação entre a implementação dos programas de $T Q M$ e a obtenção de vantagens competitivas, que não foi conclusivo com relação ao impacto de ferramentas e técnicas do $T Q M$, mas evidenciou uma relação positiva no que concerne a alguns construtos como liderança e comprometimento da alta administração e participação e envolvimento dos funcionários.

Hendricks e Singhall (1997 e 2001) também realizaram estudos que visavam evidenciar o impacto da adoção do $T Q M$ no resultado das organizações. Baseados em estudos empíricos, estes autores verificaram que a efetiva adoção do TQM pode trazer impacto positivo no crescimento das vendas e na redução dos custos (Hendricks e Singhall, 1997). Em um estudo posterior, os mesmos autores compararam o desempenho das empresas utilizando como parâmetro de análise o comportamento das ações, constatando também um resultado superior nas empresas que efetivamente implementaram o TQM (Hendricks e Singhall, 2001).

Antony e Banuelas (2002) pesquisaram os fatores-chave para a efetiva adoção dos programas Seis Sigma, bem como entender as ferramentas e técnicas que suportavam este programa. Os autores fizeram um levantamento em empresas de grande porte (mais de 1000 empregados) do Reino Unido, que priorizaram como fator de maior importância o envolvimento e comprometimento da alta administração. Outros fatores que receberam grau de importância acima da média foram as habilidades de gerenciamento de projeto, a priorização e seleção de projeto, as revisões da documentação e foco no cliente. Entre os fatores com prioridade abaixo da média estão $\mathrm{o}$ alinhamento à estratégia de negócio, treinamento $\mathrm{e}$ entendimento da metodologia Seis Sigma, ferramentas e técnicas estatísticas. 
Nilsson et al. (2001) realizaram um levantamento em 360 empresas de manufatura e 122 empresas de serviços com mais de 50 funcionários na Suécia. O objetivo da pesquisa era de examinar o impacto da gestão de pessoas, orientação a processos e orientação ao consumidor na satisfação do consumidor. Os autores verificaram que a orientação a processos tem um maior impacto positivo na satisfação do consumidor para empresas de serviço do que para empresas de manufatura. Além disto, a orientação ao consumidor tem um maior impacto positivo na satisfação do consumidor para empresas de manufatura do que para empresas de serviço. No que concerne à gestão de pessoas, observou-se um maior impacto positivo nos resultados para empresas de serviços do que para empresas de manufatura.

Sun et al. (2004) investigaram o padrão de implementação da ISO 9000 versus TQM na Europa Ocidental em três períodos, de 1992 a 2002. O primeiro levantamento foi realizado no período de 1992-1993 em 343 empresas e os outros, repetidos em 1996-1997 e em 2001-2002 (em 266 e 329 empresas, respectivamente). Dentre os resultados encontrados destaca-se que, entre 1992 e 2002, empresas européias implementaram as normas ISO $9000 \mathrm{em}$ um grau mais alto do que modelos TQM. Posteriormente, verificou-se a intenção de transição da $I S O$ para o TQM por volta da metade da década de 1990 e também no período de 2001-2002. Um dos resultados mais inquietantes foi verificado nos estágios iniciais, indicando que a implantação destes programas de qualidade não promove a melhoria aparente de desempenho.

Com base nos levantamentos disponíveis na literatura e observando-se a necessidade de dados empíricos que apresentassem o contexto brasileiro dos programas de qualidade, foi realizado o levantamento em 198 empresas de grande porte, cuja metodologia e resultados serão apresentados nas seções seguintes deste artigo.

\section{Metodologia}

A pesquisa quantitativa possui, como principal característica, a formulação de hipóteses com variáveis associadas, a partir de uma determinada teoria, possibilitando a mensuração das hipóteses. A avaliação de cada uma dar-se-á com o auxílio de ferramentas estatísticas e correlações, que auxiliarão o pesquisador na decisão de aceitá-las ou refutá-las (Bryman, 1995). O autor destaca quatro aspectos relevantes em termos de validação das hipóteses, a saber: a mensurabilidade; a causalidade; a generalização e a reprodução do experimento estudado.

Neste trabalho, foi utilizada uma pesquisa quantitativa do tipo survey. Segundo Babie (1999), a adoção desse tipo de pesquisa permite a elaboração clara e rigorosa de um modelo lógico, possibilitando ao pesquisador documentar processos causais mais complexos. Adicional- mente, este autor destaca a possibilidade da generalização, permitindo entender a população da qual a amostra foi retirada. $\mathrm{O}$ autor destaca que nesta pesquisa os estudiosos possuem, à sua disposição, um vasto número de variáveis, estando em situação bastante favorável para uma análise criteriosa da importância de cada uma delas, podendo quantificá-las e processá-las em computador.

Por outro lado, o pesquisador não possui controle sobre os eventos comportamentais e também não intervém na realização das respostas, seguindo uma sistemática pré-determinada na qual poderão ser utilizadas análises estatísticas para a avaliação dos dados. A utilização pode ser empregada na verificação de diversos temas sociais, principalmente quando associada a outros métodos.

A presente pesquisa do tipo survey foi elaborada visando responder aos questionamentos presentes nas três hipóteses deste trabalho (duas básicas e uma secundária), que são:

- $\mathrm{H}_{1}$ ) As organizações que implantaram o programa Seis Sigma são as de maior tradição em qualidade, ou seja, implantaram anteriormente outros programas de qualidade, como as normas ISO 9000 ou o TQM;

- $\mathrm{H}_{2}$ ) As empresas que mais investiram em qualidade, pela adoção de programas, obtiveram sucesso nos indicadores de desempenho da qualidade e, também, no retorno sobre o investimento realizado (ROI); e

- $\mathrm{H}_{3}$ ) As principais causas do insucesso dos programas de qualidade ISO 9000, Seis Sigma e TQM nas organizações analisadas são: a escassez de recursos financeiros para a correta implantação e o frágil apoio da direção da empresa.

\subsection{Protocolo de pesquisa}

A população foi composta das 1.000 (mil) maiores empresas brasileiras, de diversos setores industriais, consideradas potencialmente como aquelas de maior experiência na adoção de programas de gestão da qualidade, como a norma ISO 9000, o TQM e o Seis Sigma. A fonte utilizada neste trabalho foi o anuário das maiores e melhores empresas do periódico Valor Econômico, ano-base de 2003 e 2004. Inicialmente, o projeto utilizou a base de dados do anuário de 2003; porém, quando a relação de 2004 foi emitida, foi realizada uma comparação entre as duas bases, visando à identificação das diferenças. As empresas que estavam na edição de 2004 e não constavam na de 2003 receberam o questionário da pesquisa pelo correio e também por mensagem eletrônica.

O instrumento de coleta das informações foi elaborado conforme as seguintes etapas:

- O questionário foi elaborado com base no levantamento bibliográfico promovido na primeira fase da pesquisa, o que permitiu levantar as principais características dos programas de qualidade estudados neste trabalho; 
- O instrumento de pesquisa preliminar possuía 30 questões, sendo que foi realizado um pré-teste, conforme a proposta de Cooper e Schindler (2003), visando excluir as perguntas com dupla interpretação e, também, melhorar a formulação delas, dentre outros problemas. Este pré-teste foi aplicado em duas organizações, durante uma entrevista, o que possibilitou uma ampla verificação do instrumento. Neste processo de depuração, 15 questões foram reescritas e um glossário de termos, anexado ao instrumento final;

- Inicialmente, o instrumento apresenta uma carta explicativa, com os objetivos da pesquisa, tempo de preenchimento do questionário, conforme o pré-teste, o tipo de tratamento dos dados, a garantia de sigilo dos nomes das empresas e o endereço eletrônico de um glossário, com definições de termos técnicos, caso houvesse alguma dúvida nas nomenclaturas utilizadas, além dos telefones para contato entre as empresas e os pesquisadores. $\mathrm{O}$ instrumento de pesquisa em sua configuração final contém quatro blocos de perguntas. O primeiro bloco destina-se a caracterizar a empresa e o respondente da pesquisa. O segundo bloco, composto de 27 questões fechadas, destina-se à análise comparativa dos programas de gestão da qualidade sob diversos aspectos (tipos de programas adotados, motivos de implantação, valores investidos, dentre outras). O terceiro e o quarto blocos apresentam perguntas específicas sobre os programas ISO 9000 e Seis Sigma, respectivamente. Tendo como objetivo estimular as organizações a responderem o questionário, o instrumento contém uma última pergunta na qual a empresa indica se gostaria de receber o resultado final da pesquisa, enviado por correio eletrônico, o que lhes traria a possibilidade de comparação dos dados de sua organização com o resultado final desta pesquisa, além de verificar as tendências dos programas de qualidade nas empresas brasileiras; e

- O questionário foi enviado às empresas pelo correio e também por mensagem eletrônica, destinados ao departamento de qualidade das organizações. O objetivo do envio em duplicidade foi o de obter um maior retorno dos questionários, isto é, na eventualidade do instrumento impresso não atingir o seu destino, haveria ainda a possibilidade da mensagem eletrônica chegar ao responsável pelo departamento de qualidade das empresas. No caso do encaminhamento pelo correio, foi incluído um envelope devidamente selado e endereçado para a devolução do instrumento. A pesquisa abrangeu 1.000 organizações. $\mathrm{O}$ envio dos questionários foi iniciado em junho de 2004 e o término da pesquisa ocorreu em novembro do mesmo ano, totalizando cinco meses de coleta de dados.

A análise e o tratamento dos dados resultantes deste levantamento utilizaram o seguinte procedimento:
- Foram verificados todos os questionários recebidos, analisando problemas de preenchimento e corrigindoos antes da inserção das respostas no programa de computador. Os instrumentos respondidos pelas empresas que constavam da base de dados de 2003 e não estavam na edição de 2004 do anuário foram excluídos da população considerada como aceitável para a pesquisa. Foram obtidos 198 questionários válidos, cujos dados foram inseridos no programa Statistical Package for the Social Sciences (SPSS), versão 12, visando a estabelecer estatísticas descritivas da amostra; e o tratamento estatístico dos dados no referido programa, objetivando testar as hipóteses formuladas.

\section{Análise dos resultados}

A quantidade de questionários respondidos e classificados como aceitáveis para a presente pesquisa foi de 198, representando $19,8 \%$ do total de 1.000 (mil) enviados. A seguir, serão relatados os principais questionamentos presentes nos instrumentos retornados.

A Tabela 1 mostra os programas de qualidade adotados nas empresas, a quantidade deles nas organizações que participaram da pesquisa e o percentual em relação ao total respondido. Deve-se salientar que a soma dos programas de qualidade ultrapassa a quantidade de organizações estudadas (total de 198), pois, $64,1 \%$ das 198 possuem mais de um programa devidamente implementado.

$\mathrm{Na}$ categoria "Outros" estão incluídos os seguintes programas: Boas Práticas de Fabricação (BPF); Prêmio Nacional da Qualidade (PNQ); Total Productive Maintenance (TPM); SA 8000; ISO/IEC 17025; e Programas de Qualidade Personalizados, dentre outros. De acordo com a Tabela 1, pode-se também verificar que a norma ISO 9001:2000 é o programa de qualidade mais adotado nas companhias que participaram deste estudo, estando presente em $82,8 \%$ das empresas respondentes.

Tabela 1. Programas de qualidade presentes nas empresas respondentes.

\begin{tabular}{lcr}
\hline Programa de Qualidade & Quantidade & \% \\
\hline ISO 9001: 2000 & 164 & 82,8 \\
ISO 14000 & 78 & 39,4 \\
Seis Sigma & 46 & 23,2 \\
Gerenciamento por Processos & 45 & 22,7 \\
Learning Organization & 12 & 6,1 \\
TQM & 31 & 15,7 \\
ISO TS 16949 & 27 & 13,6 \\
ISO OHSAS 18001 & 18 & 9,1 \\
QS 9000 & 13 & 6,6 \\
Outros & 56 & 28,3 \\
\hline
\end{tabular}


O segundo programa mais implantado é a norma ISO 14000 (39,4\% das organizações) e o terceiro programa mais estabelecido é o Seis Sigma (23,2\% das empresas).

A Tabela 2 indica o número de empresas que adotaram apenas um programa de qualidade implementado e as combinações dos programas mais freqüentes observados nas organizações pesquisadas. Os programas analisados são: a ISO 9001:2000, a ISO 14000, o TQM e o Seis Sigma.

Na Tabela 2, pode-se observar que a ISO 9001:2000 além de ser o programa mais adotado isoladamente, também está presente nas organizações que possuem mais de um programa de qualidade implantado. As empresas que adotaram apenas o Seis Sigma declararam estar em fase de implantação de programas como a ISO 9001:2000, dentre outros. Os principais motivos que levaram as organizações a implantar os programas de qualidade estão resumidos na Tabela 3.

Analisando-se os três programas de qualidade estudados, constata-se que o principal motivo para a implantação e manutenção deles foi a "iniciativa própria para melhoria da qualidade e da produtividade", seguido da "exigência dos clientes externos", isto é, pela demanda dos clientes externos das organizações.

As ferramentas da qualidade utilizadas nas empresas pesquisadas para apoiar os programas de qualidade (a ISO 9001:2000, o Seis Sigma e o TQM) estão identificadas na Tabela 4.

Tabela 2. Número de empresas que adotaram os programas de qualidade.

\begin{tabular}{lc}
\hline \multicolumn{1}{c}{ Programa } & Quantidade \\
\hline Só ISO 9001: 2000 & 77 \\
ISO 9001:2000 e ISO 14000 & 39 \\
ISO 9001: 2000, ISO 14000 e Seis Sigma & 12 \\
ISO 14000 e Seis Sigma & 03 \\
TQM e Seis Sigma & 01 \\
ISO 9001: 2000 e TQM & 07 \\
ISO 9001: 2000 e Seis Sigma & 09 \\
ISO 9001: 2000, ISO 14000, TQM e Seis Sigma & 15 \\
Só Seis Sigma & 03 \\
\hline
\end{tabular}

As porcentagens em negrito da Tabela 4 são as ferramentas da qualidade mais utilizadas em cada programa: PDCA, o Diagrama de Causa-Efeito, o Diagrama de Pareto, o Histograma, o CEP e o Diagrama de Dispersão. Nas empresas que implantaram o Seis Sigma, observa-se que o Design for Six Sigma (DFSS) é empregado em apenas $39,1 \%$ das organizações pesquisadas. A justificativa apresentada pelas empresas é o fato desta ser uma ferramenta complexa e de difícil aplicação. Cabe ressaltar que a porcentagem de empresas que utilizam a ferramenta Análise de Variância é maior se comparada com as organizações que indicaram utilizar o DOE.

Com relação às questões sobre os valores investidos e os ganhos financeiros dos programas de qualidade, muitas empresas optaram por não respondê-las por se tratarem de dados sigilosos ou estratégicos, contudo, nas organizações que responderam, pode-se verificar que o retorno sobre o investimento realizado foi maior, ou seja, as organizações obtiveram ganhos financeiros com a implantação dos programas de qualidade. Resumindo-se os dados coletados, observa-se que $43,3 \%$ do total das companhias investiram na implantação das normas ISO 9001:2000 valores entre 50 mil e 250 mil reais e os ganhos foram superiores a um milhão de reais, em $39 \%$ das organizações. Para aqueles que implantaram o programa Seis Sigma, 39,1\% das empresas investiram entre cem mil e um milhão de reais, das quais $37 \%$ obtiveram ganho entre 250 e 500 mil reais e $13 \%$, ganhos superiores a um milhão de reais, considerando que o programa Seis Sigma é uma programa de qualidade recente. Para o TQM, os investimentos tiveram uma gama muito grande de valores (entre menos de dez mil e um milhão de reais) e o retorno financeiro em $22,6 \%$ das empresas foi entre 250 mil e superior a um milhão de reais. Portanto, pelos dados declarados pelas empresas, observou-se que os ganhos suplantaram os investimentos realizados nos programas de qualidade citados. Cabe ressaltar que os dados referentes aos ganhos das organizações com cada um dos programas de qualidade são itens declaratórios, isto é, as empresas que fizeram parte da pesquisa afirmaram que os programas ISO 9001:2000, TQM e Seis

Tabela 3. Principais motivos para implantação de programas de qualidade.

\begin{tabular}{|c|c|c|}
\hline ISO 9001:2000 & Seis Sigma & $T Q M$ \\
\hline $\begin{array}{l}\text { - "melhorar a qualidade e a produtividade" de } \\
\text { seus produtos e serviços }(87,8 \%) \text {; }\end{array}$ & $\begin{array}{l}\text { - "iniciativa própria para a melho- } \\
\text { ria da qualidade e da produtividade" } \\
(89,1 \%)\end{array}$ & $\begin{array}{l}\text { - "iniciativa própria para melhorar a quali- } \\
\text { dade e produtividade" }(96,8 \%)\end{array}$ \\
\hline $\begin{array}{l}\text { - "exigência de seus clientes" }(71,3 \%) \text {; } \\
\text { - "o atendimento à legislação onde está localiza- } \\
\text { da a companhia e o incentivo fiscal em determi- } \\
\text { nadas regiões (por exemplo, a cidade de Manaus, } \\
\text { no Amazonas)". }\end{array}$ & - “imposição das matrizes" $(39,1 \%)$. & - "exigência dos clientes" (51,6\%). \\
\hline
\end{tabular}


Sigma resultaram em ganhos financeiros, sendo que a apuração foi realizada pelas organizações, que não indicaram a metodologia utilizada nos seus cálculos.

As principais dificuldades e facilidades encontradas durante a implantação dos programas de qualidade, estão resumidas respectivamente nas Tabelas 5 e 6 .

Note-se que o "manuseio das ferramentas da qualidade" foi apontado como sendo tanto uma facilidade como uma dificuldade.

Comparando-se as dificuldades e facilidades presentes em pelo menos dois dos programas de qualidade analisados, conclui-se que os maiores aspectos negativos foram: a complexidade das operações realizadas; a indisponi- bilidade do pessoal interno para a implantação dos programas; e a confecção de documentos pertinentes a cada programa. Os itens que mais colaboraram foram: o apoio da direção, a liberação de recursos financeiros diversos e o manuseio das ferramentas da qualidade.

As dificuldades e facilidades encontradas durante a manutenção dos programas de qualidade, foram: (comparando-se as dificuldades e facilidades presentes na manutenção dos três programas) a complexidade das operações (item verificado também na implantação dos programas) e a disponibilidade dos funcionários para treinamentos, reuniões, dentre outras atividades necessárias, são as características classificadas como negativas.

Tabela 4. Ferramentas da qualidade.

\begin{tabular}{|c|c|c|c|}
\hline \multirow[t]{2}{*}{ Ferramentas da Qualidade } & \multicolumn{3}{|c|}{ Quantidade de empresas } \\
\hline & ISO 9001:2000 & Seis Sigma & $T Q M$ \\
\hline Planejamento, Execução, Controle e Análise (PDCA) & $164(100,0 \%)$ & $22(47,8 \%)$ & $28(90,3 \%)$ \\
\hline Diagrama de Causa-Efeito (Espinha de Peixe) & $134(81,7 \%)$ & $39(84,8 \%)$ & $27(87,1 \%)$ \\
\hline Diagrama de Pareto & $124(75,6 \%)$ & $35(76,1 \%)$ & $22(71,0 \%)$ \\
\hline Histograma & $103(62,8 \%)$ & $36(78,3 \%)$ & $22(71,0 \%)$ \\
\hline Controle Estatístico do Processo (CEP) & $98(59,8 \%)$ & $35(76,1 \%)$ & $24(77,4 \%)$ \\
\hline Diagrama de Dispersão & $57(34,8 \%)$ & $32(69,6 \%)$ & $22(71,0 \%)$ \\
\hline Teste de Hipóteses & $20(12,2 \%)$ & $36(78,3 \%)$ & $13(41,9 \%)$ \\
\hline Análise de Variância & $34(20,7 \%)$ & $39(84,8 \%)$ & $12(38,7 \%)$ \\
\hline Definir, Medir, Analisar, Melhorar e Controlar (DMAIC) & $14(8,5 \%)$ & $46(100 \%)$ & $06(19,4 \%)$ \\
\hline $5 \mathrm{~S}$ & $92(56,1 \%)$ & $18(39,1 \%)$ & $23(74,2 \%)$ \\
\hline Análise do Modo e Efeito da Falha (FMEA) & $72(43,9 \%)$ & $36(78,3 \%)$ & $13(41,9 \%)$ \\
\hline Box Plot & $13(7,9 \%)$ & $21(45,7 \%)$ & $02(6,5 \%)$ \\
\hline Testes não Paramétricos & $03(1,8 \%)$ & $12(26,1 \%)$ & $03(9,7 \%)$ \\
\hline Programas de Sugestão & $73(44,5 \%)$ & $15(32,6 \%)$ & $15(48,4 \%)$ \\
\hline Círculos de Controle de Qualidade & $50(30,5 \%)$ & $09(19,6 \%)$ & $13(41,9 \%)$ \\
\hline Design for Six Sigma (DFSS) & $02(1,2 \%)$ & $18(39,1 \%)$ & $03(9,7 \%)$ \\
\hline Delineamento de Experimentos (DOE) & $05(3,0 \%)$ & $30(65,2 \%)$ & $03(9,7 \%)$ \\
\hline Desdobramento da Função Qualidade (QFD) & $23(14,0 \%)$ & $14(30,4 \%)$ & $13(41,9 \%)$ \\
\hline
\end{tabular}

Tabela 5. Principais dificuldades encontradas durante a implantação dos programas de qualidade.

\begin{tabular}{|c|c|c|}
\hline ISO 9001:2000 & Seis Sigma & $T Q M$ \\
\hline $\begin{array}{l}\text { - a complexidade das operações reali- } \\
\text { zadas pelas organizações }(65,9 \%)\end{array}$ & $\begin{array}{l}\text { - a disponibilidade dos funcionários para } \\
\text { a realização de treinamentos e estudos, } \\
\text { dentre outras atividades }(45,7 \%)\end{array}$ & $\begin{array}{l}\text { - a complexidade das operações realizadas pelas } \\
\text { organizações }(64,5 \%) \text {; }\end{array}$ \\
\hline $\begin{array}{l}\text { - a disponibilidade dos funcionários } \\
\text { para a realização de treinamentos, den- } \\
\text { tre outras atividades }(62,2 \%)\end{array}$ & $\begin{array}{l}\text { - a complexidade das operações realiza- } \\
\text { das }(39,1 \%) \text {; }\end{array}$ & - a escolaridade dos colaboradores $(38,4 \%)$; \\
\hline $\begin{array}{l}\text { - a confecção dos documentos necessá- } \\
\text { rios para a certificação }(61,6 \%)\end{array}$ & $\begin{array}{l}\text { - os treinamentos internos, já que para o } \\
\text { Seis Sigma são bem mais complexos do } \\
\text { que para os demais programas de quali- } \\
\text { dade }(32,6 \%) \text {; }\end{array}$ & - a confe \\
\hline $\begin{array}{l}\text { - a apuração dos gastos e ganhos com o } \\
\text { programa }(50,0 \%)\end{array}$ & $\begin{array}{l}\text { - e o manuseio das ferramentas da quali- } \\
\text { dade }(30,4 \%) \text {. }\end{array}$ & - o pessoal interno para a implantação $(32,3 \%)$; \\
\hline $\begin{array}{l}\text { - e o pessoal interno (líderes) disponí- } \\
\text { vel para a implantação }(48,2 \%) \text {. }\end{array}$ & & $\begin{array}{l}\text { - e o manuseio das ferramentas da qualidade } \\
(29,0 \%) \text {. }\end{array}$ \\
\hline
\end{tabular}


Tabela 6. Principais facilidades encontradas durante a implantação dos programas de qualidade.

\begin{tabular}{|c|c|c|}
\hline ISO 9001:2000 & Seis Sigma & $T Q M$ \\
\hline $\begin{array}{l}\text { - o apoio da direção das empresas } \\
(84,1 \%) \text {; }\end{array}$ & $\begin{array}{l}\text { - a disponibilidade de recursos para diver- } \\
\text { sos fins como: treinamentos, material didá- } \\
\text { tico, dentre outros itens }(67,4 \%) \text {; }\end{array}$ & - o apoio da direção das empresas $(74,2 \%)$ \\
\hline $\begin{array}{l}\text { - a disponibilidade de recursos finan- } \\
\text { ceiros para diversos fins, como treina- } \\
\text { mentos, auditorias internas, material } \\
\text { didático, compra de programas esta- } \\
\text { tísticos de computador, dentre outros } \\
\text { itens }(60,4 \%) \text {; }\end{array}$ & $\begin{array}{l}\text { - o apoio da direção das empresas } \\
(65,2 \%) ;\end{array}$ & $\begin{array}{l}\text { - a disponibilidade de recursos para diversos fins } \\
\text { como: treinamentos, material didático e de apoio, } \\
\text { dentre outros itens }(71,0 \%) \text {; }\end{array}$ \\
\hline $\begin{array}{l}\text { - a consultoria contratada para auxi- } \\
\text { liar na implantação (em parte do pro- } \\
\text { grama ou em sua totalidade) }(59,8 \%) \text {; }\end{array}$ & $\begin{array}{l}\text { - a consultoria contratada para auxiliar na } \\
\text { implantação }(60,9 \%) ;\end{array}$ & - os treinamentos realizados internamente $(61,3 \%)$; \\
\hline \multirow{3}{*}{$\begin{array}{l}\text { - o manuseio das ferramentas da qua- } \\
\text { lidade; }(57,3 \%) \text {; } \\
\text { - e as auditorias internas que aponta- } \\
\text { ram diversos processos a serem me- } \\
\text { lhorados em toda a empresa }(56,1 \%) \text {. }\end{array}$} & $\begin{array}{l}\text { - a escolaridade dos colaboradores } \\
(56,5 \%) ;\end{array}$ & $\begin{array}{l}\text { - o manuseio das ferramentas da qualidade, princi- } \\
\text { palmente as técnicas estatísticas }(54,8 \%) \text {; }\end{array}$ \\
\hline & $\begin{array}{l}\text { - e os programas de computador para } \\
\text { apoio (comprados ou elaborados interna- } \\
\text { mente pelas organizações) e a confecção } \\
\text { de documentos (procedimentos, instruçôes } \\
\text { de trabalho, especificações, dentre outros) } \\
(52,2 \%) \text {. }\end{array}$ & - a confecção dos documentos $(48,4 \%)$; \\
\hline & & $\begin{array}{l}\text { - e as auditorias internas e a disponibilidade dos } \\
\text { funcionários para a realização das diversas ativida- } \\
\text { des envolvidas na implantação do programa. }\end{array}$ \\
\hline
\end{tabular}

O apoio da direção, a disponibilidade de recursos (itens analisados também na implantação dos programas), e o pessoal interno das organizações, disponibilizados para a conservação dos programas, representam as maiores facilidades encontradas para a manutenção dos programas de qualidade.

As principais alterações observadas nas empresas, após a implantação dos programas de qualidade, estão descritas a seguir. Para aquelas que implantaram o programa ISO 9001:2000, as maiores alterações nas empresas analisadas foram: maior qualidade nos produtos ou serviços e maior satisfação dos clientes externos. Para o Seis Sigma foram: maior qualidade e ganhos financeiros. Para o TQM, as maiores modificações foram: maior satisfação dos clientes externos e internos e maior qualidade. Analisando-se os três programas conjuntamente, conclui-se que o benefício mais presente foi a melhoria na qualidade.

As perspectivas de futuro dos programas de qualidade nas empresas que participaram da pesquisa, foram: a "perspectiva de futuro" para todos os programas analisados é de "ampliação" para outras áreas da empresa, ou seja, existem organizações em que a ISO 9001:2000, por exemplo, está implantada em alguns departamentos, portanto, a expansão ocorreria para outros setores da companhia. Existem também casos de organizações que são compostas por diversas plantas industriais, nem todas certificadas, existindo, por conseguinte, a possibilidade de difusão para outras unidades do grupo. Para o
Seis Sigma e o $T Q M$, a perspectiva mais proeminente é a ampliação do programa para outros setores (como por exemplo, departamentos administrativos) ou plantas da organização.

Com relação à premiação dos colaboradores pela participação nos programas de qualidade, observou-se que: a maioria das organizações está optando por premiar seus colaboradores com cartas, medalhas, certificados, dentre outras formas; e pouquíssimas companhias estão premiando seus funcionários com valores financeiros (itens verificados nos três programas analisados). Uma porcentagem expressiva das empresas está considerando o empenho dos empregados nos programas de qualidade na avaliação de desempenho anual, ou seja, uma atuação expressiva na implantação e manutenção dos programas de qualidade pode reverter em promoções ou ajustes salariais indiretamente, conforme o previsto na avaliação de desempenho anual, como exemplo.

Analisando-se somente as empresas que implantaram o Seis Sigma, tem-se os resultados descritos a seguir: as empresas que adotaram o Seis Sigma utilizam a denominação descrita na literatura sobre o tema para os integrantes do programa e que a grande maioria dos funcionários envolvidos possui escolaridade significativa, ou seja, aproximadamente $60 \%$ possuem o curso superior completo ou são pós-graduados.

A grande maioria dos colaboradores envolvidos no programa Seis Sigma foi indicada pelas chefias diretas 
$(63,2 \%)$. Deve-se salientar que algumas empresas não responderam a essa pergunta nem forneceram os motivos. O acompanhamento dos projetos, visando avaliar sua efetividade, teve as seguintes indicações: $26,1 \%$ das companhias realizam o acompanhamento de seus projetos semestralmente e $19,6 \%$ trimestralmente, isto é, certifica-se de que os ganhos financeiros adquiridos com os projetos Seis Sigma continuam sendo verdadeiros, após determinado período de tempo. Deve-se salientar, também, que todas as empresas que adotaram o programa Seis Sigma responderam a essa pergunta. Todas as organizações analisadas que implantaram o Seis Sigma realizam a verificação financeira dos projetos pelos setores contábeis da organização, em conjunto com os departamentos envolvidos.

Este estudo tem interesse em testar a seguinte hipótese:

$\left.H_{1}\right)$ As organizações que implantaram o programa Seis Sigma são as de maior tradição em qualidade, ou seja, implantaram anteriormente outros programas de qualidade como as normas ISO 9000 ou o TQM.

O principal objetivo desta hipótese é verificar se a implementação do programa Seis Sigma está associada, ou não, à implementação de outros programas de qualidade anteriormente, como sugere a literatura. Para testar esta hipótese, foram realizados testes de associação (pela estatística Qui-quadrado) (Agresti, 1990) .

Por meio dos dados analisados, constata-se que a adoção do Seis Sigma não está associada ao fato da empresa possuir certificação ISO 9000 (Qui-quadrado $=0,161 \mathrm{e}$ $\mathrm{p}=0,688)$. No entanto, esta hipótese foi validada para os programas TQM e ISO 14000, ou seja, a implantação do programa do Seis Sigma está associada ao fato da empresa já ter implementado o programa TQM (Qui-quadrado $=29,849$ e $p<0,001$. De modo similar, a implantação do programa Seis Sigma está associada ao fato da empresa já possuir a certificação ISO 14000 (Qui-quadrado $=16,736$ e $\mathrm{p}<0,001)$.

Portanto, pode-se concluir, pelo exposto anteriormente, que a hipótese 1 foi confirmada para os programas $T Q M$ e ISO 14000, ou seja, a implantação do programa Seis Sigma está relacionada com a implementação prévia destes dois programas de qualidade. Por outro lado, faltam evidências empíricas para atestar que existe relação direta entre a implementação do Seis Sigma com a obtenção prévia das normas ISO 9000. Os dados indicam ainda que as organizações que adotaram o Seis Sigma estavam mais familiarizadas com outros programas de qualidade, bem como na utilização de ferramentas da qualidade, confecção de documentos, dentre outras habilidades, conforme exposto no tópico anterior deste artigo. Além da hipótese $\mathrm{H}_{1}$, existe interesse em testar a hipótese $\mathrm{H}_{2}$.

$\mathrm{H}_{2}$ ) As empresas que mais investiram em qualidade, pela adoção de programas, obtiveram sucesso nos indicadores de desempenho da qualidade e, também, no retorno sobre o investimento realizado (ROI).

A análise desta hipótese foi feita primeiramente na questão do instrumento de pesquisa que verifica as "Principais alterações nas empresas após a implantação dos programas", cujas respostas poderiam ser: ganhos financeiros, maior produtividade, maior qualidade, maior satisfação dos clientes externos, maior satisfação dos clientes internos, aumento da participação no mercado e realização de exportações. Com base nos dados oriundos dos questionários das 198 empresas que responderam à pesquisa survey, verificou-se que: para o programa ISO 9001:2000 as maiores alterações nas empresas analisadas foram: maior qualidade nos produtos ou serviços e maior satisfação dos clientes externos. Para o Seis Sigma, foram: maior qualidade e ganhos financeiros. Para o $T Q M$, as maiores modificações foram: maior satisfação dos clientes externos e internos e maior qualidade.

Para as análises estatísticas de retorno sobre os investimentos, foram utilizadas as questões referentes aos investimentos e aos retornos financeiros obtidos. Cabe salientar que as empresas declararam os montantes envolvidos, informando no instrumento de pesquisa os valores totais investidos e o retorno financeiro referentes a cada um dos programas em questão (ISO 9001:2000, $T Q M$ e Seis Sigma), não sendo detalhada a metodologia que cada empresa utilizou para contabilizar esses dados. Avaliando o retorno financeiro, com base nos valores declarados pelas empresas, os dados demonstram que os ganhos foram superiores aos valores investidos. Para verificar se as empresas que mais investem nos programas são as que mais obtêm retornos, correlações de Spearman foram calculadas (Conover, 1980) com os resultados da amostra das 198 organizações respondentes. Para tanto, foram utilizadas duas perguntas do instrumento (questão que indaga "Qual o nível e as principais alterações que ocorreram na empresa após a implantação dos programas?" e a pergunta sobre "Quais os ganhos financeiros com o programa?"). Os resultados estão resumidos na Tabela 7.

Conforme a Tabela 7, verifica-se que os valores investidos no programa Seis Sigma estão diretamente correlacionados com os ganhos financeiros (em qualquer um dos três programas de qualidade). No programa Seis Sigma, os valores investidos também estão correlacionados com a satisfação dos clientes internos e externos.

Além das duas hipóteses principais, há interesse em testar a seguinte hipótese secundária:

$\mathrm{H}_{3}$ ) As principais causas do insucesso dos programas de qualidade ISO 9000, Seis Sigma e TQM nas organizações analisadas são: a escassez de recursos financeiros para a correta implantação e o frágil apoio da direção da empresa. 
Tabela 7. Correlações Spearman (valor investido x ganho financeiro).

\begin{tabular}{llcc}
\hline Questões 17 e 21 do Instrumento & Spearman & p-value \\
\hline programa & $\begin{array}{l}\text { Valores investidos x } \\
\text { Ganhos financeiros quan- } \\
\text { tificados } 9000\end{array}$ & 0,560 & $<\mathbf{0 , 0 0 1}$ \\
programa & $\begin{array}{l}\text { Valores investidos x } \\
\text { TQM }\end{array}$ & 0,888 & $\mathbf{0 , 0 0 1}$ \\
& $\begin{array}{l}\text { Ganhos financeiros quan- } \\
\text { tificados }\end{array}$ & & \\
programa & $\begin{array}{l}\text { Valores investidos x Sa- } \\
\text { Seis Sigma }\end{array}$ & 0,394 & $\mathbf{0 , 0 1 9}$ \\
& $\begin{array}{l}\text { Valores investidos x Sa- } \\
\text { tisfação clientes internos }\end{array}$ & 0,338 & $\mathbf{0 , 0 4 7}$ \\
& $\begin{array}{l}\text { Valores investidos x } \\
\text { Ganhos financeiros quan- } \\
\text { tificados }\end{array}$ & & \\
& & 0,464 & $\mathbf{0 , 0 2 2}$ \\
\hline
\end{tabular}

Apenas 06 (seis) empresas tiveram seu certificado ISO 9000 cancelado, sendo que todas alegaram, como principal motivo, a falta de recursos financeiros para: a contratação de consultoria especializada para apoiar o processo de implantação; a realização dos treinamentos específicos na versão 2000 da norma em todos os níveis participantes; e a contratação de pessoal especializado para a coordenação geral do programa. Nas seis organizações, os responsáveis pela direção da certificação estavam subordinados à gerência industrial que alegava não possuir recursos financeiros suficientes, conhecimentos técnicos sobre a nova versão da norma para a confecção e acerto de diversos itens como a documentação, a realização das auditorias internas, dentre outros, e tempo disponível para a implantação da nova versão da norma.

Outro motivo apontado como principal fator para a não realização da certificação na versão 2000 foi o pouco apoio recebido da direção da empresa, no sentido de não conscientizar seus colaboradores da importância advinda com a atualização da norma. Três das seis empresas analisadas afirmaram que poderiam ter realizado a implantação da nova versão da norma, apesar da falta de diversos recursos, se a empresa tivesse feito um grande esforço, incluindo todos os setores da organização, aliado a um forte apoio motivacional por parte da direção.

O cancelamento do programa Seis Sigma foi verificado em apenas 01 (uma) organização, com a alegação de o programa não ter cumprido as metas financeiras estabelecidas a curto prazo. O principal motivo alegado para o fracasso foi a falha na implantação do programa, especificamente nos treinamentos internos, que ocasionaram projetos deficientes em sua conclusão. Os referidos treinamentos foram realizados pela empresa de consultoria que foi contratada para a implantação do programa, sendo que a quantidade de horas destinadas aos treinamentos, em geral, foi reduzida em $30 \%$, com o objetivo de diminuir o custo total do programa.
Outro motivo apontado como contribuinte do insucesso foi o baixo apoio recebido da direção da empresa, que não realizou uma avaliação criteriosa nas metas estabelecidas no início do projeto, ou seja, as diretrizes estabelecidas estavam difíceis de serem cumpridas a curto prazo, necessitando de uma nova avaliação das metas, incluindo um período maior para sua consolidação.

As companhias que tiveram o $T Q M$ excluído somam 07 (sete), sendo que, na maioria dos casos, em cinco empresas, houve a substituição por outros programas de qualidade; em 03 delas, pelo Seis Sigma. A alegação básica apresentada por cinco empresas foi que não houve o cumprimento dos objetivos de melhoria de qualidade estabelecidos no início do projeto. As causas mais relevantes que determinaram o cancelamento do $T Q M$ e a substituição por outro programa foram: as falhas nos treinamentos dos colaboradores (poucas horas destinadas à utilização das ferramentas estatísticas da qualidade, fazendo com que houvesse resistência a sua utilização e uso incorreto); a determinação superestimada dos indicadores de desempenho determinados pela direção da empresa (as metas estabelecidas para a qualidade dos produtos e serviços eram bastante audaciosas e, portanto, difíceis de serem alcançadas) e o pouco apoio da direção das empresas.

\section{Conclusão}

A análise do tipo survey foi efetuada pelo envio de 1000 (mil) questionários, sendo que retornaram 198 $(19,8 \%)$ para análise dos dados.

A hipótese "as organizações que implantaram o programa Seis Sigma são, em geral, as de maior tradição em qualidade, ou seja, implantaram anteriormente outros programas de qualidade como as normas ISO 9000 ou o $T Q M$ " foi considerada como verdadeira, pois os dados comprovaram que a adoção do Seis Sigma está associada à implantação anterior de outros programas de qualidade (o TQM e a norma ISO 14000).

A hipótese "as empresas que mais investiram em qualidade, pela adoção de programas, obtiveram sucesso nos indicadores de desempenho da qualidade e, também, no retorno sobre o investimento realizado (ROI)" foi considerada verdadeira, pois foram verificados ganhos financeiros e de qualidade nas empresas que participaram da pesquisa.

A norma ISO 9000 está diretamente correlacionada com os ganhos obtidos (correlação de Spearman com $\mathrm{p}<0,001)$. O TQM possui os valores investidos nos programas diretamente correlacionados com os ganhos financeiros (correlação de Spearman com p <0,05).

Os valores investidos no programa Seis Sigma estão diretamente correlacionados com satisfação dos clientes internos, externos e os ganhos financeiros oriundos do 
programa (correlação de Spearman com p's $<0,05$ ).

A hipótese secundária deste trabalho "as principais causas do insucesso dos programas de qualidade ISO 9000, Seis Sigma e $T Q M$ nas organizações analisadas foram: a escassez de recursos financeiros para a correta implantação e o frágil apoio da direção da empresa" foi considerada como sendo verdadeira.

As empresas que tiveram seu certificado ISO 9000 cancelado foram apenas 06 (seis), alegando como principal motivo a falta de recursos financeiros para diversos fins. Outro motivo apontado foi o baixo apoio recebido da direção da empresa, para as diversas atividades inerentes à certificação. Três das seis empresas analisadas disseram que poderiam ter realizado a implantação da nova versão, apesar da falta de recursos, se houvesse um grande esforço da empresa, incluindo todos os setores da organização, aliado a um forte apoio motivacional por parte da direção. O cancelamento do programa Seis Sigma foi verificado em apenas 01 (uma) organização, com a justificativa de não ter cumprido as metas financeiras estabelecidas a curto prazo. O principal motivo que contribuiu para o insucesso dos programas de qualidade foi a redução de custos de $30 \%$ na quantidade de horas para os treinamentos internos, que ocasionaram projetos deficientes em sua conclusão. Outro motivo apontado como colaborador do insucesso foi o baixo apoio recebido da direção da empresa, que não realizou uma avaliação criteriosa nas metas estabelecidas no início do projeto, ou seja, as diretrizes estabelecidas estavam difíceis de serem cumpridas a curto prazo, necessitando de um período maior para consolidação das metas dispostas.

As companhias que tiveram o TQM cancelado somam 07 (sete), sendo que, na maioria dos casos (cinco empre- sas), houve a substituição por outros programas de qualidade. A justificativa básica apresentada por cinco empresas foi que não houve o cumprimento dos objetivos de melhoria de qualidade estabelecidos no início do projeto. As causas mais relevantes que determinaram o cancelamento do TQM foram: as falhas nos treinamentos dos colaboradores; a determinação superestimada dos indicadores de desempenho determinados pela direção da empresa e o pouco apoio recebido dos gestores das organizações, demonstrando baixo comprometimento com o programa.

O estudo nas empresas respondentes demonstrou que existe uma tendência de que o programa Seis Sigma deva ser amplamente estudado e difundido nos próximos anos, devido aos ganhos financeiros proporcionados, conforme verificado nas empresas analisadas.

Este estudo apresenta as limitações inerentes ao método de pesquisa adotado, ou seja, os resultados obtidos não devem ser generalizados, porém, acredita-se que possam contribuir significativamente para um maior e melhor entendimento dos fatores que exercem influências nos programas de melhoria da qualidade adotados nas empresas brasileiras.

A atual pesquisa abordou apenas as grandes empresas brasileiras. Uma possível extensão é repetir este levantamento nas pequenas e médias organizações nacionais. Outro futuro projeto seria a aplicação da atual metodologia em outros países, objetivando a comparação entre nações.

\section{Agradecimentos}

Os autores agradecem ao CNPq e à Fapesp pelo apoio financeiro e aos revisores anônimos pelas sugestões dadas.

\section{Referências Bibliográficas}

\section{AGRESTI, A. Categorical data analysis. New York: Wiley,} 1990.

AHIRE, S.; GOLHAR, D.; WALLER, M. Development and validation of TQM constructs. Decision Science, v. 27, n. 1, p. 23-56, 1996.

ANTONY, J; BANUELAS, R. Key ingredients for the effective implementation of Six Sigma program. Measuring Business Excellence, v. 6, n. 4, p. 20-27, 2002.

BABBIE, E. R. Métodos de pesquisa de survey. Belo Horizonte: UFMG, 1999. 519 p.

BRYMAN, A. Research methods and organization studies. London: Routledge, 1995. 352 p.

CARVALHO, M. M.; PALADINI, E. P. Gestão da qualidade: teoria e casos. Rio de Janeiro: Campus, 2005. 304 p.
COMITÊ BRASILEIRO DA QUALIDADE - CB-25. Total de certificados ISO 9000 emitidos e válidos no Brasil e no mundo. Disponível em: <http://www.abnt.gov. br/cb25>. Acesso em: 20 de dezembro 2005.

CONOVER W. J. Practical nonparametric statistics. 2. ed. Nova York: Wiley, 1980. 592 p.

CONNOR, G. Benefiting from Six Sigma. Manufacturing Engineering, v. 130, n. 2, p. 53-59, 2003.

COOPER, N. P., NOORNAN, P. Do teams and Six Sigma go together. Quality Progress, v. 130, n. 2, p. 25-28, June, 2003.

COOPER, R. D., SCHINDLER, P. S. Método de pesquisa em administração. 7. ed. São Paulo: Bookman, 2003. $640 \mathrm{p}$. 
CROSBY, P. B. Qualidade, falando sério. São Paulo: McGraw-Hill, 1990. 270 p.

DEMING, W. E. Qualidade: a revolução da administração. Rio de Janeiro: Marques-Saraiva, 1990. 392 p.

DOBB, F. ISO 9000 registration step-by-step. USA: Butterworth-Heineman, 2002. 292 p.

FEIGENBAUM, A. V. Total Quality Control. New York: McGraw-Hill, 1954. 863 p.

FLYNN, B. B.; SCHOEDER, R. G.; SAKAKIBARA, S. A framework for Quality Management Research and associated measurement instrument. Journal of Operations management, v. 11, n. 4, p. 339-366, 1994.

GARVIN, D. A. Managing quality: the strategic and competitive edge. EUA, New York: Harvard Business School, 1988. 319 p.

HAMMER, M. Process management and the Six Sigma. MIT Sloan Management Review, p. 26-33, Winter, 2002.

HENDRICKS, K. B.; SINGHALL, V. R. The long-run stock price performance of firms with effective TQM programs. Management Science, v. 47, n. 3, p. 359-369, 2001.

HENDRICKS, K. B.; SINGHALL, V. R. Does implementing an effective $T Q M$ program actually improve operating performance? - Empirical evidence from firms that have won quality awards. Management Science, v. 43, n. 9, p. 258-1274, 1997.

ISHIKAWA, K. Controle de qualidade total à maneira japonesa. 6. ed. Rio de Janeiro: Campus, 1997. 221 p.

JURAN, J. M.; GRYNA, F. M. Controle da qualidadehandbook. 4. ed. São Paulo: Makron Books \& McGrawHill, 1992.378 p.

LANDON, T. 13 steps to certification in less than a year. Quality Progress, p. 32-42, Mar. 2003.

LOVE, P. E. D. Overcoming the problems associated with quality certification. Construction Management \& Economics, Mar. 2003.

MARTÍNEZ-LORENTE, A. R.; Dewhurst, F.; Dale, B. G. Total Quality Management: origins and evolution of the term. The TQM Magazine, v. 10, n. 5, p. 378-386, 1998.

MOTWANI, F. Critical factors and performance measures of TQM. The TQM Magazine, v. 13, n . 4, p. 292-300, 2001.

NILSSON, L.; JOHNSON, M.; GUSTAFFSON, A. The impact of quality practices on customer satisfaction and business results: product versus service organizations. Journal of Quality Management, v. 6, n. 18, p. 5-27, 2001.

OLEXA, R. Flying high with Six Sigma. Manufacturing Engineering, v. 130, n. 2, p. 69-73, 2003.

PANDE, P. S., NEUMAN R. P., CAVANAGH, R. R. Estratégia Seis Sigma. Como a GE, a Motorola e outras grandes empresas estão aguçando seu desempenho. Rio de Janeiro: Qualitymark, 2001. 472 p.

PEREZ-WILSON, M. Seis Sigma compreendendo o conceito, as implicações e os desafios. Rio de Janeiro: Qualitymark, 2000. $284 \mathrm{p}$.

PHILLIPS, E. J. Six Sigma: the breakthrough management strategy revolutionizing the world's top corporations. Consulting Management, v. 13, n. 4, p. 57-59, 2002.

POWEL, T. C. Total Quality Management as competitive advantage: a review and empirical study. Strategic Management Journal, v. 16, n. 1, p. 15-37, 1995.

PYZDEK, T. 6-Sigma a um passo da perfeição. HSM Management, p. 86-90, maio/junho, 2003.

ROBITAILLE, D. E. Do the transition to ISO 9000:2000. Quality Digest, p. 29-32, May, 2003.

ROTONDARO, R. G. "Método básico: uma visão geral" (Org.). Seis Sigma estratégia gerencial para a melhoria dos processos, produtos e serviços. São Paulo: Atlas, 2002, p. 23-48. 376 p.

SHANKAR, N. K. ISO 9000: integration Europe and North America. European Quality, v. 9, n. 4, p. 20-29, Sept. 2003.

SHIBA, S.; GRAHAN, A.; WALDEN, D. TQM: quatro revoluções na gestão da qualidade. São Paulo: Bookman, 1997. $402 \mathrm{p}$.

SUN, H.; LI, S.; HO, K.; GESTERN, F.; HANSEN, P.; FRICK, J. The trajectory of implementing ISO 9000 standards versus total quality management in Western Europe. International Journal of Quality \& Reliability Management, v. 21, n. 2, p. 131-153, 2004.

WARNACK, M. Continual improvement programs and ISO 9001:2000. Quality Progress, p. 42-50, Mar. 2003.

WATSON, J. J. Satisfaction through Six Sigma. Engineered Systems, v. 20, n. 3, p. 94-98, Mar. 2003.

WELCH, J. Jack Welch por Jack Welch. HSM Management, n. 41, p. 18-30, Nov./Dec. 2003a.

WELCH, J. Os difusores: GE e Jack Welch. HSM Management, n. 38, p. 86-90, May/June, 2003b. 


\title{
IMPLEMENTATION OF QUALITY PROGRAMS: A SURVEY IN LARGE SIZE BRAZILIAN COMPANIES
}

\begin{abstract}
This research aims to identify the main trends in the implementation of Quality Programs in Brazilian companies and is based on the most widely known and implemented models, such as the certification of quality systems according to the ISO 9000 Program, the Six Sigma and the TQM Program (Total Quality Management Program). This study provides a comparative and critical analysis of the implementation of those systems in Brazilian organizations as well as the existing relations among them, their complementary and redundancies. This issue is extremely relevant nowadays as companies invest heavily in different programs in order to improve quality, but still face huge difficulties to evaluate their strategic impact as well as their respective added value. In order to carry out this study, we have evaluated the references available about the subject. The methodology used in this research was based on a quantitative survey. The population of this search consists of a list the 1000 top Brazilian companies ranked according to their published sales figures according to "Ranking Valor 1.000", published in Valor Econômico yearbook (2004). This analysis assumed that new emerging quality management models could be found in this list Responses to questionnaires and to interviews made during visits to those companies were analyzed employing a statistical software. The analysis points out that the companies had implemented the Six Sigma Program are those with the strongest tradition in quality programs since they had earlier implemented other quality programs; as more the companies invest in quality programs more is the improvement in their performance; and the main causes for failures in ISO 9000, Six Sigma and TQM programs implementation were due to lack of financial resources for a correct implementation and a fragile support provided by the company management team.
\end{abstract}

Keywords: quality programs, Six Sigma, ISO 9000, TQM. 
